\title{
The Influence of Government-Led Industrial Agglomeration on the Efficiency of Resource Allocation-Evidence from 30 Provinces in China over 2000-2017
}

\author{
Long Wei, Yanan Wu \\ School of Economics, Wuhan University of Technology, Wuhan, China \\ Email: 1287652367@qq.com
}

How to cite this paper: Wei, L., \& Wu, Y. N. (2021). The Influence of Government-Led Industrial Agglomeration on the Efficiency of Resource Allocation-Evidence from 30 Provinces in China over 2000-2017. American Journal of Industrial and Business Management, 11, 157-171.

https://doi.org/10.4236/ajibm.2021.112010

Received: January 15, 2021

Accepted: February 7, 2021

Published: February 10, 2021

Copyright $\odot 2021$ by author(s) and Scientific Research Publishing Inc. This work is licensed under the Creative Commons Attribution International License (CC BY 4.0).

http://creativecommons.org/licenses/by/4.0/

\begin{abstract}
Under the development mode of government-led industrial agglomeration, most enterprises are motivated by the purpose of obtaining "policy rent", which has a negative impact on the improvement of resource allocation efficiency. Therefore, based on Hsieh \& Klenow's resource mismatch theory, this paper measures the resource mismatch index of 30 provinces and empirically tests the impact of government-led industrial agglomeration on resource allocation efficiency. The results show that the tendency of "free-ride" caused by government intervention leads to the U-shaped change trend of industrial agglomeration on resource allocation efficiency. This paper discusses the feasible options to improve the efficiency of resource allocation under the joint action of market mechanism and moderate government intervention.
\end{abstract}

\section{Keywords}

Government-Led, Industrial Agglomeration, Resource Allocation Efficiency, Resource Mismatch

\section{Introduction}

China's economy has achieved more than 40 years of rapid growth, but the development model is mainly driven by resources inputs, and the transformation from rough development to high-quality development has become an inevitable requirement for the establishment of a new stage and a new development model. In the context of continuous economic expansion, the development mode of industrial agglomeration is gradually becoming the main driving force of econom- 
ic development. On this basis, it is a key issue to explore how to use industrial agglomeration to improve the resource allocation efficiency and transform to a new growth model.

Since Hsieh and Klenow's (2009) pioneering study on resource allocation efficiency, much attention has been paid to this area of research, By measuring the labor and capital mismatch index, H\&K found that TFP could increase by $30 \%$ $50 \%$, if the capital and labor resources in China's manufacturing industry were allocated at the same level as in the United States. Domestic scholars have also conducted research on the improvement of resource allocation efficiency in terms of capital allocation (Zhang, 2013; Wang \& Yuan, 2014) and labor allocation (Yuan \& Xie, 2011; Cao \& Lou, 2012).

Regarding the research on how industrial agglomeration improves resource allocation efficiency, according to Krugman (1991), it is known that industrial clusters form clusters of related industries through backward and forward linkages, which generate positive externalities for enterprises in the same area. It guides the agglomeration of resources in a certain geographical area, which affects the flow of resources such as labor and capital, thus affecting resource allocation efficiency (Ji et al., 2016). However, after Marshall (1890) first proposed the concept of "Industrial District" (Industrial District), Markusen (1996) proposed three typical industrial agglomeration methods: "Marshall District", "Wheeled District" and "Satellite District". There has been little research on the key forces driving the formation of industrial agglomerations and the resulting differences in resource allocation efficiency. The market-driven industrial agglomeration formed spontaneously by the endogenous market is driven by enterprises' pursuit of maximizing their own interests, and its upstream and downstream industries are more closely related, and the external spillover benefits within the agglomeration area are strengthened. The agglomeration level is further strengthened by enhancing the positive feedback effect itself (Li, 2014). In China, the government can have some influence on the formation and development process of industrial agglomeration. For the purpose of political performance, the government intervenes in the allocation of production resources with policy preferences and other measures to promote the formation of industrial agglomeration. In this kind of industrial agglomeration formed under the guidance of the government, most enterprises tend to form superficial "pile-ups" for the purpose of obtaining "policy rent", and often lack correlation and independent selectivity. The vicious circle of competition reduces the efficiency of industrial agglomeration and can cause problems such as resource mismatch (Zheng et al., 2008; Shi \& Shen, 2013). Under the system of fiscal decentralization and the evaluation of economic performance as an indicator, some local governments protect local industries and blindly carry out disorderly industrial planning without considering their own development advantages, forming superficial inefficient industrial agglomeration, generating many problems such as local protection, market segmentation and duplicate construction, obstruction of 
the flow of capital, labor and other resources in the agglomeration area, and resource allocation is inefficient (Bai et al., 2004; Zhou, 2004; Liu, 2012).

Under the influence of both market mechanism and government intervention, the effect generated by industrial agglomeration will be subsequently reduced and the resource allocation may be distorted. In this paper, we take government behavior as an entry point, based on Hsieh \& Klenow's resource mismatch theory, and use panel data of 30 provinces to empirically analyze how government-led industrial agglomeration affects resource allocation efficiency and explore the differences in the impact of industrial agglomeration on different distortions of resource allocation, to explore feasible options for improving resource allocation efficiency under the joint effect of market mechanism and moderate government intervention.

\section{Mechanisms}

Under the government-led industrial agglomeration development model, in order to complete the performance assessment objectives and the pursuit of fiscal revenue, the government actively plans industrial estate and provides financial subsidies, tax incentives and other preferential policies for enterprises to achieve the purpose of attracting investment. A large number of inefficient enterprises "pile up" to form false industrial agglomerations for the purpose of seeking "policy rent", and the low-end agglomeration phenomenon is amplified due to the enterprise selection effect. Inefficient enterprises in the agglomeration area crowd out the production resources of high-efficiency enterprises, and the latter are forced to reduce their market share or withdraw from production, resulting in inefficient resource allocation. This kind of government-led industrial agglomeration tends to have a weak agglomeration effect, but the speed of agglomeration is fast, too fast agglomeration will bring significant crowding effect. The crowding effect will cause vicious competition among enterprises for production resources, resulting in obstruction of free flow of resources, shortage of resources, rising resources prices, and inefficient resource allocation (Zhou \& Zhu, 2013). The government-led industrial agglomeration model does not fully consider its own locational advantages, and problems such as industrial isomorphism, repeated construction, and waste of resources are frequent, which reduces the positive effects generated by industrial agglomeration (Xiao \& Li, 2018).

With the advantages of preferential policies and infrastructure, China's development zones have had a positive impact in guiding industrial agglomeration and optimizing industrial structure. After 1992, there were too many development zones in the country, and this rapid expansion exceeded the needs of actual economic development and regional affordability. There were obvious problems such as inefficient resource allocation, uneconomic scale of inputs, and weak factor-driven economic growth (Liu \& Zhao, 2015). The main motive for enterprises to move into the development zones is to obtain policy preferences. Under 
the condition that the main motive is "policy rent", the correlation of enterprise actors in the development zones is weak, and "pile-up" clusters do not produce agglomeration effects in the general sense, and the problems of duplicate construction and vicious competition are intensified. The phenomenon of resource mismatch is becoming increasingly serious in national development zones. Some of the development zones did not fully consider their own location advantages, industrial development status, and inter-industry correlation when they were established, and failed to form a reasonable division of labor, resulting in a mismatch of resources and the phenomenon of industrial isomorphism, which cannot promote the transformation and upgrading of industrial structure.

\section{Methodology and Data}

\subsection{Model Design}

$$
\ln \tau_{i t}=\alpha_{0}+\alpha_{1}+\beta_{1} a g g_{i t}+\beta_{2} a g g_{i t} * g o v_{i t}+\gamma x_{i t}+\mu_{i}+\lambda_{t}+\varepsilon_{i t}
$$

where $i, t$ stands for provinces, years. $\tau_{k i t}$ and $\tau_{l i t}$ represent capital and labor mismatch index. $a g g_{i t}$ represents the level of industrial agglomeration, and $x_{i j t}$ is a set of control variables. $\mu_{i}, \lambda_{t}, \varepsilon_{i t}$ represent individual effects, the time fixed effect, and error term.

\subsection{Variable Selection}

\subsubsection{Measurement of Industrial Agglomeration Index}

$$
\operatorname{Agglo}_{i t}=\left(\frac{M_{i t}}{M_{t}}\right) / \frac{P_{i t}}{P_{t}}
$$

where, $M_{i t}$ is the manufacturing population in region $i$ at time $t . P_{i t}$ is the employed population in region $i$ at year $t$, and $M_{t}$ and $P_{t}$ are the national manufacturing population and employed population at year $t$, The higher the value of this index, the higher the level of industrial agglomeration

\subsubsection{Measurement of Government Intervention Index}

Financial development has a role in spreading risk and easing information asymmetry, and higher financial market efficiency can promote industrial agglomeration. Under the fiscal decentralization system, the Chinese government has the willingness and ability to influence the investment and financing behavior of enterprises through loans from financial institutions. The "political" loans affect the credit of state-owned enterprises, and the government's administrative intervention in the allocation of credit resources, it can contribute to industrial agglomeration. Therefore, the index of government intervention in this paper is represented using the ratio of loan balances of financial institutions to GDP.

\subsubsection{Measurement of Resource Allocation Efficiency Index}

The measurement of resource allocation efficiency uses the framework of Hsieh \& Klenow (2009) to calculate, and uses the capital mismatch index $\tau_{K i}$, labor 
mismatch index $\tau_{L i}$ to measure, which is calculated as follows:

To simplify the analysis, it is assumed that the C-D production function of firms in industry $i$ is scale payoff invariant: $\beta_{K i}+\beta_{L i}=1$ The production function of industry $i$ is constructed as:

$$
Y_{i}=A_{i} K_{i}^{\alpha_{i}} L_{i}^{1-\alpha_{i}}
$$

where, $A_{i}, K_{i}, L_{i}, \alpha_{s}$ and $Y_{i}$ represent total factor productivity, capital input, labor input, capital-output elasticity of industry $S$, output:

$r_{K i}$ and $r_{L i}$ are absolute factor price distortion coefficients, which indicate the additive condition when factor prices are relatively undistorted.

$$
r_{K i}=\frac{1}{1+\tau_{K i}}, \quad r_{L i}=\frac{1}{1+\tau_{L i}}
$$

$\hat{r}_{K i}$ and $\hat{r}_{L i}$ are the relative factor price distortion coefficients, which indicate the relative state of factor price distortion compared to the economy's average

$$
\hat{r}_{K i}=\left(\frac{K_{i}}{K}\right) /\left(\frac{S_{i} \beta_{K i}}{\beta_{K}}\right), \hat{r}_{L i}=\left(\frac{L_{i}}{L}\right) /\left(\frac{S_{i} \beta_{L i}}{\beta_{L}}\right)
$$

$\frac{K_{i}}{K}$ and $\frac{L_{i}}{L}$ are the actual ratios of capital and labor in total capital and labor in region $S_{i}=\frac{P_{i} Y_{i}}{Y}$ is the proportion of output in region $i$ in the output of the whole economy. $\beta_{K}=\sum_{i}^{N} S_{i} \beta_{K i}$ and $\beta_{L}=\sum_{i}^{N} S_{i} \beta_{L i}$ are the output-weighted capital and labor contribution values. $\frac{S_{i} \beta_{K i}}{\beta_{K}}$ and $\frac{S_{i} \beta_{L i}}{\beta_{L}}$ are the theoretical ratios used by region $i$ in achieving efficient allocation of capital and labor. The ratio can measure the degree of resource misallocation in region $i$. This ratio is greater than 1, which indicates that the resource use cost in region $i$ is higher and the resource is under-allocated compared with the whole economy, and vice versa exceeds the theoretical level of effective allocation.

According to the above calculation method, to calculate the efficiency of resource allocation, it is necessary to first estimate the values of capital and labor factor output elasticities $\beta_{K}$ and $\beta_{L}$, refer to the method of Zhao et al. (2006) for the specific calculation.

The assumed C-D production function is scale payoff invariant.

$$
Y_{i t}=A K \beta_{i t}^{K i} L_{i t}^{1-\beta_{K i}}
$$

Adding the individual effect $\mu_{i}$, and the time effect $\lambda_{t}$ :

$$
\ln \left(\frac{Y_{i t}}{L_{i t}}\right)=\ln A+\beta_{K i} \ln \left(\frac{K_{i t}}{L_{i t}}\right)+u_{i}+\lambda_{t}+\varepsilon_{i t}
$$

Output variable $\left(Y_{i t}\right)$. The GDP deflator is used to calculate the real GDP of each province using 2000 as the base period.

Capital input quantity $\left(K_{i t}\right)$. Using the perpetual inventory method to calculate the fixed capital stock for each province. 


$$
K_{t}=I_{t} / P_{t}+\left(1-\delta_{t}\right) K_{t-1}
$$

$K_{t}$ represents the fixed capital stock in the current period, $\mathrm{I}_{t}$ is the total fixed capital formation in the current period, $P_{t}$ is the fixed asset investment price index, $\delta_{t}$ represents the depreciation rate 9.6\%, and $K_{t-1}$ represents the fixed capital stock in the previous period. The base period capital stock refers to the algorithm of Zhang et al. (2004).

Labor input volume $\left(L_{i t}\right)$. Using the arithmetic mean of current year and previous year-end employment.

Using the panel data for each province from 2000-2018, the least squares dummy variable method was used to estimate the capital and labor output elasticities for the 30 provinces by the above method. Since there are two cases of positive and negative resource allocation mismatch, when the mismatch index is negative, it indicates over-allocation of resources, and conversely, resources are under-allocated (Ji et al., 2016). Because there are positive and negative results of resource allocation efficiency measurements, absolute values need to be processed, and the more serious the resource mismatch situation is, the larger the absolute value is.

\subsubsection{Control Variables}

Knowledge spillover (edu): university students are an indirect knowledge transfer mechanism to realize knowledge spillover from universities to enterprises, using "the number of university students in each province" as the knowledge spillover variable; labor cost (wage), using the average wage of employees in each province to represent labor cost; industrial structure (third). The upgrade of industrial structure can promote the flow of resources from low-productivity sectors to high-productivity sectors, which will lead to better allocation of resources and improve the resource allocation efficiency, using the ratio of tertiary industry output value in GDP; foreign direct investment (fdi), the introduction of foreign capital improves the level of market competition, and the increase in marketization promotes the circulation of resources, facilitates the reallocation of resources, using the ratio of foreign direct investment in GDP. The level of marketization (market), using the ratio of government fiscal spending in GDP, The lower the ratio, the higher the degree of marketization; per capita GDP (PGDP): reflects the development level between regions; total population (pop): reflects the difference of labor force between regions.

According to the above method, using equilibrium panel data for 30 Chinese provinces from 2000-2017, the raw data are obtained from the China Statistical Yearbook and the statistical yearbooks of each province in previous years. The capital mismatch index $\tau_{k}$ and labor mismatch index $\tau_{l}$ are measured for each province. Table 1 describes in detail the capital mismatch index $\tau_{k}$ and labor mismatch index $\tau_{l}$ for each province in 2017. From the specific data in the table, it can be seen that there are positive and negative figures, with large differences in the magnitude of the absolute values, indicating that there is a 
Table 1. Capital, labor mismatch index by province in 2017.

\begin{tabular}{|c|c|c|c|c|c|}
\hline \multirow{2}{*}{ province } & \multicolumn{2}{|c|}{ Resource Mismatch } & \multirow{2}{*}{ province } & \multicolumn{2}{|c|}{ Resource Mismatch } \\
\hline & $\tau_{k}$ & $\tau_{l}$ & & $\tau_{k}$ & $\tau_{l}$ \\
\hline Beijing & -0.06208 & 1.378177 & Henan & -0.27277 & -0.35616 \\
\hline Tianjin & -0.05559 & 1.149163 & Hubei & -0.02485 & -0.25791 \\
\hline Hebei & -0.24261 & 0.230173 & Hunan & 0.142884 & -0.32956 \\
\hline Shanxi & -0.29012 & -0.14694 & Guangdong & 0.177125 & -0.29387 \\
\hline Inner Mongolia & -0.35318 & 0.617585 & Guangxi & -0.46083 & -0.0616 \\
\hline Liaoning & 0.055185 & 0.381654 & Hainan & -0.45274 & 0.159678 \\
\hline Jilin & -0.39598 & 0.362966 & Chongqing & 0.108446 & 0.199806 \\
\hline Heilongjiang & 0.129693 & 0.028173 & Sichuan & 0.140754 & -0.2733 \\
\hline Shanghai & 0.260021 & 1.019494 & Guizhou & -0.45174 & -0.35289 \\
\hline Jiangsu & 0.025623 & 1.112748 & Yunnan & -0.39228 & -0.37412 \\
\hline Zhejiang & 0.358982 & 0.129551 & Shaanxi & -0.28084 & -0.03714 \\
\hline Anhui & -0.05699 & -0.27835 & Gansu & -0.30314 & -0.10396 \\
\hline Fujian & 0.000214 & 0.177617 & Qinghai & -0.65576 & -0.01952 \\
\hline Jiangxi & -0.05545 & -0.12819 & Ningxia & -0.7131 & -0.03638 \\
\hline Shandong & -0.002 & 0.258106 & Xinjiang & -0.50124 & 0.068738 \\
\hline
\end{tabular}

mismatch between capital and labor in all 30 provinces, with differences between different regions, and that there are both under- and over-allocation of resources. The larger absolute value indicates that the mismatch is more serious in the region, while the smaller absolute value indicates that there is a lighter resource distortion. In terms of capital allocation, the degree of capital mismatch is less in the eastern region, while the degree of capital mismatch is higher in the central and western regions. Due to the high degree of marketization in the east, capital can be better allocated under the action of the mechanism in the market, so the capital allocation efficiency is high. Most of the central and western regions are negatively mismatched, indicating that the price of capital in these regions is lower than normal, the amount of capital input is higher than the theoretical ratio at efficient allocation, and capital is over-allocated. In terms of labor allocation, the labor mismatch is higher in the eastern regions. Among them, the labor mismatch index of Beijing, Shanghai, Jiangsu and Tianjin is greater than 1, and the inefficiency of labor allocation is serious. Due to the rapid and fast economic development in the eastern region, there is a large labor shortage, but the labor cost keeps rising and there are obstacles to a certain extent in the labor flow between different regions, so the labor allocation in some eastern regions is insufficient and does not reach the optimal configuration. In the central and western regions, most of the regions show less than 0 in terms of capital and labor allocation, which indicates that there is an over allocation of capital and labor. The regional policies implemented by the state for the central and western 
regions, but due to the factors of backward infrastructure and low technology in the central and western regions, the mismatch of resources is exacerbated to some extent, and the resources invested in these regions do not reach the corresponding output, resulting in the allocation of capital and labor not achieving the optimal allocation.

\section{Empirical Results}

\subsection{Baseline Results}

Since there is a certain path dependence in the improvement of resource allocation efficiency, this paper establishes a dynamic panel for regression. To address the possible endogeneity problem, the systematic GMM is selected for estimation and the results are subjected to Arellano-Bond, Sargan tests. Arellano-Bond sequence correlation tests to verify the existence of second and higher order autocorrelation in residual sequences. The p-value of $\mathrm{AR}(1)$ in Table 2 is less than 0.1 and the p-value of $\operatorname{AR}(2)$ is greater than 0.1 , which passed the autocorrelation test. Sargan test for validity of the instrumental variables, if the p-value is greater than 0.1 , it means that the original hypothesis is accepted at $10 \%$ significance level, i.e. the selected instrumental variables are valid. The value of 1 for the Sargan test in Table 3 indicates that the instrumental variables are valid. The model passed the serial correlation test and the Sargan test, so the estimation results of the systematic GMM are valid.

According to the estimation results in Table 3, the first column analyzes the effect of industrial agglomeration on the capital mismatch index and labor mismatch index, controlling only for the core variables. The results show that the primary term coefficient is significantly negative and the squared term is significantly positive, and there is a significant " $U$ " shaped relationship between

Table 2. Main variable definition.

\begin{tabular}{|c|c|c|}
\hline Variable & Symbol & Definition \\
\hline Capital Mismatch Index & $\tau_{k}$ & Efficiency of capital allocation by province \\
\hline Labor Mismatch Index & $\tau_{l}$ & Efficiency of Labor allocation by province \\
\hline Knowledge spillover & edu & The number of university students in each province \\
\hline Labor cost & wage & Average wage of employees by province \\
\hline Industrial structure & third & Ratio of tertiary sector output in GDP by province \\
\hline $\begin{array}{l}\text { Foreign direct } \\
\text { investment }\end{array}$ & fdi & Ratio of foreign direct investment in GDP by province \\
\hline $\begin{array}{l}\text { The level of } \\
\text { marketization }\end{array}$ & market & Ratio of government fiscal spending in GDP by province \\
\hline Per capita GDP & PGDP & GDP per capita by province \\
\hline Total population & pop & Total population by province \\
\hline $\begin{array}{l}\text { Government } \\
\text { intervention }\end{array}$ & Gov & $\begin{array}{l}\text { Loan balance of financial institutions as a percentage of } \\
\text { GDP by province }\end{array}$ \\
\hline
\end{tabular}


Table 3. Results of full-sample estimates.

\begin{tabular}{|c|c|c|c|c|c|c|}
\hline \multirow{2}{*}{$\begin{array}{c}\text { Explanatory } \\
\text { Variable }\end{array}$} & \multicolumn{3}{|c|}{ Explained Variable $\left|\tau_{k}\right|$} & \multicolumn{3}{|c|}{ Explained Variable $\left|\tau_{k}\right|$} \\
\hline & (1) & (2) & (3) & (1) & (2) & (3) \\
\hline \multirow[t]{2}{*}{ L. $\tau_{k}$} & 1.00096 & $0.983^{\star * *}$ & $0.964^{\star * *}$ & & & \\
\hline & $(32.32)$ & (15.08) & (10.38) & & & \\
\hline \multirow[t]{2}{*}{ L. $\tau_{l}$} & & & & $0.90301^{* * *}$ & $0.895^{* * *}$ & $0.714^{* * *}$ \\
\hline & & & & $(268.85)$ & $(57.72)$ & (67.05) \\
\hline \multirow[t]{2}{*}{ agg } & $-0.0642^{\star * *}$ & $-0.0503^{\star * *}$ & $-0.0805^{\star * *}$ & $-0.0942^{* * *}$ & $-0.115^{\star * *}$ & $-0.221^{\star *}$ \\
\hline & $(-9.31)$ & $(-3.80)$ & $(-3.04)$ & $(-14.01)$ & $(-4.63)$ & $(-2.29)$ \\
\hline \multirow[t]{2}{*}{ Agg2 } & $0.0282^{\star * *}$ & $0.0240^{* * *}$ & $0.0252^{\star * *}$ & $0.0491^{* * *}$ & $0.0550^{* * *}$ & $0.0454^{\star *}$ \\
\hline & (10.77) & $(4.22)$ & $(3.35)$ & (35.68) & $(7.60)$ & $(2.17)$ \\
\hline \multirow[t]{2}{*}{ market } & & $-0.203^{* * *}$ & $-0.139^{* *}$ & & 0.112 & $0.389^{*}$ \\
\hline & & $(-2.60)$ & $(-2.45)$ & & $(0.91)$ & $(1.67)$ \\
\hline \multirow[t]{2}{*}{ fdi } & & $-0.0118^{* * *}$ & $-0.00460^{\star *}$ & & $0.0148^{* * *}$ & $0.0730^{* * *}$ \\
\hline & & $(-3.18)$ & $(-2.20)$ & & (5.43) & $(3.67)$ \\
\hline \multirow[t]{2}{*}{ edu } & & $-0.0372^{* * *}$ & $-0.0160^{\star * *}$ & & $-0.00789^{*}$ & $0.00106^{* *}$ \\
\hline & & $(-4.08)$ & $(-3.62)$ & & $(-1.12)$ & $(2.44)$ \\
\hline \multirow[t]{2}{*}{ third } & & $-0.0437^{* * *}$ & $-0.00116^{\star *}$ & & $0.0867^{\star * *}$ & $0.00704^{* * *}$ \\
\hline & & $(-3.67)$ & $(-2.25)$ & & (5.13) & (5.39) \\
\hline \multirow[t]{2}{*}{ gov } & & $0.0328^{*}$ & 0.0689 & & 0.0753 & $0.571^{\star}$ \\
\hline & & (1.93) & $(1.07)$ & & $(0.91)$ & $(1.95)$ \\
\hline \multirow[t]{2}{*}{ pop } & & -0.0577 & $0.356^{\star}$ & & 0.0215 & $0.280^{\star *}$ \\
\hline & & $(-0.60)$ & (1.64) & & $(0.37)$ & $(2.56)$ \\
\hline \multirow[t]{2}{*}{ pgdp } & & $-0.0508^{\star}$ & $-0.0804^{* *}$ & & $0.0253^{*}$ & -0.0347 \\
\hline & & $(-1.86)$ & $(-2.50)$ & & (2.19) & $(-1.01)$ \\
\hline \multirow[t]{2}{*}{ wage } & & $0.0601^{\star * *}$ & $0.00975^{* * *}$ & & $-0.0389^{* * *}$ & $-0.0395^{\star * *}$ \\
\hline & & $(3.78)$ & $(3.32)$ & & $(-3.62)$ & $(-4.69)$ \\
\hline \multirow[t]{2}{*}{ Govªgg } & & & $0.0336^{\star *}$ & & & $0.225^{\star * \star}$ \\
\hline & & & $(2.67)$ & & & $(2.71)$ \\
\hline \multirow[t]{2}{*}{ cons } & & $0.302^{* * *}$ & -2.812 & $0.680^{* * *}$ & -0.420 & $-2.130^{* * *}$ \\
\hline & & $(4.82)$ & $(-1.58)$ & (18.63) & $(-1.02)$ & $(-2.84)$ \\
\hline $\operatorname{AR}(1)$ & 0.0185 & 0.0189 & 0.0155 & 0.0235 & 0.0211 & 0.0173 \\
\hline $\operatorname{AR}(2)$ & 0.2696 & 0.6957 & 0.4158 & 0.1956 & 0.2034 & 0.6960 \\
\hline Sargan & 1.0000 & 1.0000 & 1.0000 & 1.0000 & 1.0000 & 1.0000 \\
\hline $\mathrm{N}$ & 510 & 510 & 510 & 510 & 510 & 510 \\
\hline
\end{tabular}

Standard errors in parentheses. ${ }^{* *} \mathrm{p}<0.01,{ }^{* *} \mathrm{p}<0.05,{ }^{*} \mathrm{p}<0.1$.

the two. When the industrial agglomeration exceeds the optimal scale, the scale effect will be changed into the crowding effect, and the crowding effect will be 
highlighted. There is an optimal ratio of production resources inputs, and the crowding effect will cause the production resources to deviate too much or too little from the optimal ratio, and the factor ratio will be imbalanced and the degree of resource mismatch will be intensified. After adding control variables and interaction terms in the second and third columns, this " $U$ "-shaped relationship is still significant. As the level of industrial agglomeration increases, the resource allocation efficiency tends to improve first and then intensify, while excessive industrial agglomeration and pile-up of enterprises will cause resource mismatch and reduce resource allocation efficiency. The second column of results controls for core and control variables, and the level of marketization is significantly negative on the capital mismatch index, indicating that as the level of marketization increases, the improvement of market mechanism helps to improve the level of market competition and give full play to the guiding role of price mechanism, and the efficiency of capital flow increases, thus improving the capital allocation efficiency. The effect of knowledge spillover on resource allocation efficiency is significantly negative. Based on the knowledge spillover mechanism of human capital flow, the mutual exchange of knowledge talents between regions promotes the diffusion of knowledge, and the labor force structure is optimized, which in turn improves the resource allocation efficiency. Foreign direct investment has a significantly negative effect on the capital mismatch index and a significantly positive effect on the labor mismatch index. The introduction of foreign investment helps to improve the capital shortage phenomenon in regional development, and the capital allocation structure reaches a more reasonable state, which improves the degree of resource mismatch. However, at the same time, a series of preferential policies provided by local governments to attract foreign investment may distort the market allocation of resource and intensify resource mismatch. The effect of industrial structure upgrading on capital mismatch is significantly negative, improving the degree of capital mismatch, and on labor mismatch is significantly positive, intensifying the degree of labor mismatch. It may lie in the fact that the upgrading of industrial structure is only a simple increase in the proportion of tertiary industry, and the internal structure is not reasonable, which does not improve the efficiency of resource allocation. The productivity level of labor-intensive service industry is low, and the transfer of labor factors to the tertiary industry does not achieve better allocation, which intensifies the phenomenon of resource mismatch. The effect of labor cost on capital mismatch is significantly positive and labor mismatch is significantly negative, indicating that the rise of labor cost promotes the improvement of labor allocation efficiency and intensifies capital mismatch. The increase in labor cost promotes labor mobility and resource allocation to higher productivity regions, improving labor mismatch. After adding the interaction term in the third column, the coefficient of the interaction term is significantly positive and the sign of the core variable does not change, indicating that industrial agglomeration under government intervention can exacerbate resource mismatch. In China, under the fiscal decentralization system, local governments intervene admi- 
nistratively in the allocation of credit resources, and "political" lending gives higher credit quotas to state-owned enterprises. The expansion of the scale of financial development is based on the scale of credit from the state sector constantly crowding out credit from the non-state sector. As the scale of financial development increases, potential government intervention increases, and the distorting effect of industrial agglomeration on resource allocation is further enhanced. Due to the government's role in the market mechanism, it is easy to lead to over-investment of lending enterprises, and the distortion effect of the preferential policies provided, a large number of enterprises are mainly motivated by the "policy rent", forming a false industrial agglomeration, which cannot play the expected effect on the improvement of resource allocation efficiency and intensify resource mismatch.

\subsection{Subsample Results}

Industrial agglomeration may have different effects on the resource mismatch phenomenon in the two cases of under-allocation $(\tau>0)$ and over-allocation $(\tau<$ 0 ) of resources. According to the difference of positive and negative mismatch, two sub-samples are divided into "over-allocation of resources" and "under-allocation of resources", and regressions are conducted to analyze whether there are different effects. The results are shown in Table 4 . The results of systematic GMM estimation show that industrial agglomeration has a significant positive effect in the over-allocated regions and a negative effect on the under-allocated regions. For regions with over-allocated resources, the flow efficiency of production resource such as capital and labor increases under the effect of external economic effect generated by industrial agglomeration, which increases the possibility of external market entry, and the external market makes regional resource allocation reach a more reasonable level and improves resource allocation efficiency. Industrial agglomeration generates scale effect, prompting

Table 4. Results of over- and under-resourcing estimates.

\begin{tabular}{|c|c|c|c|c|}
\hline \multirow{2}{*}{ Variable } & \multicolumn{2}{|c|}{ Over-resourced provinces } & \multicolumn{2}{|c|}{ Under-resourced provinces } \\
\hline & $\tau_{k}$ & $\tau_{l}$ & $\tau_{k}$ & $\tau_{l}$ \\
\hline \multirow[t]{2}{*}{ L. $\tau$} & $0.7793^{\star * *}$ & $1.18111^{\star * *}$ & $0.9973^{\star * *}$ & $0.9121^{\star * *}$ \\
\hline & $(7.04)$ & $(6.68)$ & $(3.37)$ & $(40.21)$ \\
\hline \multirow[t]{2}{*}{ Agg } & $-0.0259^{\star * *}$ & $-0.1746^{* * *}$ & $0.0202^{\star *}$ & $0.0743^{\star *}$ \\
\hline & $(-3.32)$ & $(-2.90)$ & $(2.07)$ & $(2.33)$ \\
\hline Control variables & YES & YES & YES & YES \\
\hline $\operatorname{AR}(1)$ & 0.0830 & 0.0830 & 0.0830 & 0.0403 \\
\hline $\operatorname{AR}(2)$ & 0.2587 & 0.2230 & 0.2456 & 0.2719 \\
\hline Sargan & 1.0000 & 1.0000 & 1.0000 & 1.0000 \\
\hline
\end{tabular}

Standard errors in parentheses. ${ }^{* * *} \mathrm{p}<0.01,{ }^{* *} \mathrm{p}<0.05,{ }^{*} \mathrm{p}<0.1$. 
the center and the peripheral hinterland to continuously expand the economic scope and improve the technology level. The formation of industrial agglomeration on this basis can absorb redundant resources while improving resource mismatch. The initial condition for the formation of industrial agglomeration is to have regional comparative advantages, and the areas with insufficient resource allocation do not have such advantages, and industrial agglomeration instead reduces the efficiency of resource allocation. Due to the insufficient resource allocation itself, it is also difficult to achieve more reasonable resource allocation by increasing the level of industrial agglomeration, and reducing industrial agglomeration may also reduce the mismatch caused by insufficient resources.

\subsection{Robustness Check}

To test the robustness of the regression results, a robustness test is required, referring to Bai and Liu (2018), the capital distortion coefficient and labor distortion coefficient of the factor market are used as explanatory variables to measure the efficiency of resource misallocation, and the regression method still uses the SYS-GMM dynamic panel model for regression. The capital and labor distortion coefficients are calculated as follows.

$$
\begin{aligned}
& \text { dist }_{k}=\frac{M P_{K}}{r}-1=\beta_{K i} \frac{p_{i} y_{i}}{r K_{i}} \\
& \text { dist }_{L}=\frac{M P_{K}}{\omega}-1=\beta_{L i} \frac{p_{i} y_{i}}{\omega_{i} L_{i}}-1
\end{aligned}
$$

$p_{i} y_{i}$ is the gross product of each region; $r$ is the price of capital, i.e., the level of interest rate, taken as $10 \%$ (Hsieh \& Klenow, 2009); $\omega_{i}$ is the price of labor, expressed as the average wage of employed persons in each region; $M P_{K}$ and $M P_{L}$ represent the marginal output of capital and labor. $\beta_{K i}$ and $\beta_{L i}$ represent the elasticity of output of capital and labor. If the calculated index is greater than 0 , indicating that the real reward of factors is less than the deserved reward, and there is negative distortion; conversely, there is positive distortion. The factor market distortion coefficients need to be treated as absolute values because there are both positive and negative cases. The results are shown in Table 3.

According to the estimation results in Table 5, the impact of industrial agglomeration on resource allocation efficiency has significantly negative coefficients for the primary term, significantly positive coefficients for the squared term, and significantly positive coefficients for the interaction term. The regression results pass the serial autocorrelation test and the Sargan test, indicating that the estimation results of SYS-GMM are valid. After replacing the measure of resource allocation efficiency as the explanatory variable, the regression results are still valid and consistent with the above, indicating that the conclusions of this paper are robust. 
Table 5. Robustness tests.

\begin{tabular}{|c|c|c|c|c|}
\hline \multirow{2}{*}{$\begin{array}{c}\text { Explanatory } \\
\text { Variable }\end{array}$} & \multicolumn{2}{|c|}{ Explained Variable $\left|\tau_{k}\right|$} & \multicolumn{2}{|c|}{ Explained Variable $\left|\tau_{t}\right|$} \\
\hline & (1) & (2) & (1) & (2) \\
\hline \multirow[t]{2}{*}{$\mathrm{L}$. } & $0.8267^{* * *}$ & $0.959^{* * *}$ & 0.8662 & $0.800^{* * *}$ \\
\hline & (74.39) & $(44.68)$ & (359.63) & (38.09) \\
\hline \multirow[t]{2}{*}{ agg } & $-0.0019^{* * *}$ & $-0.00177^{* *}$ & $-0.0351^{\star * *}$ & $-0.0462^{\star * *}$ \\
\hline & $(-4.97)$ & $(-3.17)$ & $(-2.86)$ & $(-3.08)$ \\
\hline \multirow[t]{2}{*}{ Agg2 } & $0.0013^{* * *}$ & $0.000393^{* * *}$ & $0.0096^{* * *}$ & $0.0151^{* * *}$ \\
\hline & $(7.50)$ & (4.37) & $(3.21)$ & (3.94) \\
\hline \multirow[t]{2}{*}{ market } & & $-0.00278^{\star * *}$ & & -0.00302 \\
\hline & & $(-3.38)$ & & $(-0.03)$ \\
\hline \multirow[t]{2}{*}{ fdi } & & $0.0432^{* *}$ & & 0.0100 \\
\hline & & (2.48) & & $(0.90)$ \\
\hline \multirow[t]{2}{*}{ edu } & & $-0.0800^{\star * *}$ & & $-0.0120^{\star \star \star}$ \\
\hline & & $(-3.62)$ & & $(-2.94)$ \\
\hline \multirow[t]{2}{*}{ third } & & 0.0173 & & $-0.00182^{* * *}$ \\
\hline & & $(0.23)$ & & $(-3.06)$ \\
\hline \multirow[t]{2}{*}{ gov } & & 0.09825 & & $0.0924^{\star \star}$ \\
\hline & & $(1.62)$ & & $(2.16)$ \\
\hline \multirow[t]{2}{*}{ pop } & & 0.00275 & & $0.0285^{\star *}$ \\
\hline & & (1.07) & & $(2.00)$ \\
\hline \multirow[t]{2}{*}{ pgdp } & & $-0.0770^{\star \star \star}$ & & $0.00115^{\star * *}$ \\
\hline & & $(-4.41)$ & & $(3.77)$ \\
\hline \multirow[t]{2}{*}{ wage } & & 0.0113 & & $-0.00150^{\star * \star}$ \\
\hline & & $(0.13)$ & & $(-5.11)$ \\
\hline \multirow[t]{2}{*}{ Govªgg } & & $0.00148^{\star *}$ & & $0.0251^{* *}$ \\
\hline & & (2.59) & & (1.96) \\
\hline \multirow[t]{2}{*}{ cons } & -0.1678 & -0.0612 & $0.1337^{\star * *}$ & $-0.200^{\star * *}$ \\
\hline & $(-15.40)$ & $(-1.63)$ & (57.39) & $(-9.62)$ \\
\hline $\operatorname{AR}(1)$ & 0.0113 & 0.0684 & 0.0011 & 0.0017 \\
\hline $\operatorname{AR}(2)$ & 0.6512 & 0.5386 & 0.2859 & 0.2692 \\
\hline Sargan & 1.0000 & 1.0000 & 1.0000 & 1.0000 \\
\hline $\mathrm{N}$ & 510 & 510 & 510 & 510 \\
\hline
\end{tabular}

Standard errors in parentheses. ${ }^{* *} \mathrm{p}<0.01,{ }^{* *} \mathrm{p}<0.05,{ }^{*} \mathrm{p}<0.1$.

\section{Conclusion and Suggestion}

Based on Hsieh \& Klenow's resource mismatch theory, this paper shows through mechanism analysis and empirical analysis that the scale effect dominates in the early stage of industrial agglomeration, which is conducive to improving the resource mismatch phenomenon. But with the deepening of government intervention in the formation of industrial agglomeration, after the industrial agglomeration exceeds the optimal scale, the scale effect is transformed into a crowding ef- 
fect, resulting in a low level of resource allocation efficiency. The impact of industrial agglomeration on resource allocation efficiency has a double effect, showing a significant "U"-shaped relationship. This effect is inevitably related to the over-agglomeration of industries and the clustering of enterprises. By introducing the interaction term between industrial agglomeration and government intervention, it is found that industrial agglomeration guided by government action is not the spontaneous formation of agglomeration areas guided by agglomeration externalities, and a large number of enterprises form false industrial agglomeration with the main motive of "policy rent", which leads to the reduction of resource allocation efficiency. Although government intervention may cause resource mismatch, it does not deny the active role of the government in the economy, market stability, financial risks, and a series of macro issues depend on the government's market regulation. How to regulate government intervention and maintain the balanced development of market and government is the current problem.

Based on the empirical results of this paper, the following policy recommendations are proposed: 1) Resource allocation efficiency will deteriorate due to the existence of excessive government intervention, so the endogenous market forces should be used to gradually guide the formation of a market-oriented spontaneous industrial agglomeration model, promote the free flow of various resource, and realize the optimal allocation of resources. 2) The government needs to formulate the agglomeration policy oriented to the optimal allocation of resources according to the different industrial development and local capital and labor allocation among regions. The impact of industrial agglomeration on resource allocation efficiency has a dual role. Therefore, if the government wants to guide the formation of efficient industrial agglomeration, it should pay attention to the reasonable layout of regional industries, optimize the industrial structure, avoid the deterioration of resource allocation efficiency caused by "pile-up" industrial agglomeration, and realize the better development of industrial agglomeration mode.

There are different forms of industrial agglomeration, such as diversified agglomeration and specialized agglomeration, and different agglomeration methods may have different effects on resource allocation efficiency, which can be further discussed in depth on the basis of this paper.

\section{Acknowledgements}

Sponsored by China National Fund for National Social Science Research Project: On the Core theory of Global Layout for China's Strategic Emerging Industry, 17BJL015.

\section{Conflicts of Interest}

The authors declare no conflicts of interest regarding the publication of this paper. 


\section{References}

Bai, C., Du, Y. J., Tao, Z. G., \& Tong, Y. T. (2004). Determinants and Trends of Local Protectionism and Regional Concentration of Industries. Economic Research, 4, 29-40.

Bai, J. H., \& Liu, Y. Y. (2018). Can Foreign Direct Investment Improve China’s Resource Mismatch. China Industrial Economy, 1, 60-78.

Cao, Y. S., \& Lou, D. W. (2012). Resource Mismatch, Structural Change and Economic Transformation in China. China Industrial Economy, 10, 5-18.

Hsieh, C., \& Klenow, P. (2009). Misallocation and Manufacturing TFP in China and India. Quarterly Journal of Economics, 124, 1403-1448. https://doi.org/10.1162/qjec.2009.124.4.1403

Ji, S. H., Zhu, Y. M., \& Zhang, X. (2016). Research on the Improvement Effect of Industrial Agglomeration on Resource Mismatch. China Industrial Economy, 6, 73-90.

Krugman, P. (1991). Increasing Returns and Economic Geography. The Journal of Political Economy, 99, 483-499. https://doi.org/10.1086/261763

Li, X. L. (2014). An Empirical Analysis of Marketization, Industrial Agglomeration and Environmental Pollution. Statistical Research, 31, 39-45.

Liu, R. M. (2012). State-Owned Enterprises, Implicit Subsidies and Market Segmentation: Theoretical and Empirical Evidence. Management World, 4, 21-32.

Liu, R. M., \& Zhao, R. J. (2015). Do National High-Tech Zones Promote Regional Economic Development?-A Validation Based on Double Difference Method. Management World, 8, 30-38.

Markusen, A. (1996). Sticky Places in Slippery Space: A Typology of Industrial Districts. Economic Geography, 72, 293-313.

Marshall, A. (1890). The Principles of Economics. London: Macmillan.

Shi, B., \& Shen, K. R. (2013). Government Intervention, Economic Agglomeration and Energy Efficiency. Management World, No. 10, 6-18+187.

Wang, L. H., \& Yuan, L. (2014). Does Capital Mismatch Induce Total Factor Productivity Loss. Statistical Research, 31, 11-18.

Xiao, X. Z., \& Li, S. S. (2018). The Corrective Effect of Industrial Agglomeration on Manufacturing Resource Mismatch: Linear or Nonlinear? Industrial Economics Research, 5, $1-13$.

Yuan, Z. G., \& Xie, D. D. (2011). Analysis of the Impact of Labor Force Mismatch on TFP in China. Economic Research, 46, 4-17.

Zhang, J., Wu, G. Y., \& Zhang, J. P. (2004). Estimation of Interprovincial Physical Capital Stock in China: 1952-2000. Economic Research, 10, 35-44.

Zhang, P. (2013). A Study of Inter-Industry Resource Mismatch in China's Industrial Sector. Investment Research, 32, 15-27.

Zhao, Z. Y., Liu, X. L., \& Lv, B. Y. (2006). Estimation of Factor Output Elasticity in China. Economic Theory and Economic Management, 6, 5-11.

Zheng, J. H., Gao, Y. Y., \& Hu, X. W. (2008). The Clustering of Enterprises, Technological Upgrading and Economic Performance: An Empirical Analysis of the Clustering Effect in Development Zones. Economic Research, 5, 33-46.

Zhou, L. (2004). Incentives and Cooperation of Government Officials in the Promotion Game: A Discussion of the Reasons for the Persistence of Local Protectionism and Duplication in China. Economic Research, 6, 33-40.

Zhou, S. Q., \& Zhu, W. P. (2013). Does Industrial Agglomeration Necessarily Bring Economic Efficiency: Scale Effect and Crowding Effect. Industrial Economics Research, 3, 12-22. 